\title{
Between- and within-population variations in thermal reaction norms of the coccolithophore Emiliania huxleyi
}

\author{
Yong Zhang, ${ }^{1}$ Regina Klapper, ${ }^{2, a}$ Kai T. Lohbeck, ${ }^{1,2}$ Lennart T. Bach, ${ }^{1}$ Kai G. Schulz,, b \\ Thorsten B. H. Reusch, ${ }^{2}$ and Ulf Riebesell $1, *$ \\ ${ }^{1}$ Biological Oceanography, GEOMAR Helmholtz-Centre for Ocean Research Kiel, Kiel, Germany \\ ${ }^{2}$ Evolutionary Ecology of Marine Fishes, GEOMAR Helmholtz-Centre for Ocean Research Kiel, Kiel, Germany
}

\begin{abstract}
Thermal reaction norms for growth rates of six Emiliania huxleyi isolates originating from the central Atlantic (Azores, Portugal) and five isolates from the coastal North Atlantic (Bergen, Norway) were assessed. We used the template mode of variation model to decompose variations in growth rates into modes of biological interest: vertical shift, horizontal shift, and generalist-specialist variation. In line with the actual habitat conditions, isolates from Bergen (Bergen population) grew well at lower temperatures, and isolates from the Azores (Azores population) performed better at higher temperatures. The optimum growth temperature of the Azores population was significantly higher than that of the Bergen population. Neutral genetic differentiation was found between populations by microsatellite analysis. These findings indicate that E. huxleyi populations are adapted to local temperature regimes. Next to between-population variation, we also found variation within populations. Genotype-by-environment interactions resulted in the most pronounced phenotypic differences when isolates were exposed to temperatures outside the range they naturally encounter. Variation in thermal reaction norms between and within populations emphasizes the importance of using more than one isolate when studying the consequences of global change on marine phytoplankton. Phenotypic plasticity and standing genetic variation will be important in determining the potential of natural $E$. huxleyi populations to cope with global climate change.
\end{abstract}

The increase of atmospheric carbon dioxide concentrations is projected to result in a global mean temperature increase by up to $4^{\circ} \mathrm{C}$ until the end of this century (Intergovernmental Panel on Climate Change 2013), resulting in a concomitant warming of the surface ocean. Ocean warming will affect marine organisms and likely result in migration, adaptation, or extinction (Thomas et al. 2012; Reusch 2014; Winter et al. 2013). The coccolithophore Emiliania huxleyi is the most abundant calcifying phytoplankton species in contemporary oceans. It is distributed from the tropics to high-latitude regions and from midocean to inshore waters with temperature ranges from $2^{\circ} \mathrm{C}$ to $28^{\circ} \mathrm{C}$ (McIntyre and Bé 1967). A recent genome study revealed large genomic differences in isolates from several ocean regions and suggests that E. huxleyi is a species complex that may partly explain its wide distribution range (Read et al. 2013). A wealth of studies has focused on the effects of ocean change on growth, calcification, and photosynthesis in E. huxleyi (Riebesell and Tortell 2011). However, most rely on a single isolate that is considered to be representative for the E. huxleyi species complex. It has been argued that besides the phenotypic variability of a single isolate, the genotypic

*Corresponding author: uriebesell@geomar.de

Present addresses:

a Department of Safety and Quality of Milk and Fish Products, Federal Research Institute for Nutrition and Food, Max RubnerInstitute, Hamburg, Germany

b Centre for Coastal Biogeochemistry, School of Environmental Science and Management, Southern Cross University, Lismore, NSW, Australia variability that is commonly found between different isolates will also be important to understand responses of natural phytoplankton populations to ocean change (Kremp et al. 2012; Schaum et al. 2012; Tatters et al. 2013).

Various factors, such as nutrient concentrations (Fernández et al. 1996) or frontal boundaries formed by ocean currents (Palumbi 1994), may drive the distribution of phytoplankton in the oceans. As a consequence of ocean boundaries, populations may get separated and allow local adaptation to the respective environment (Leducq et al. 2014). Populations can adapt to their local environment either through selection of new, beneficial mutations or through selection on existing genetic variation (Collins et al. 2013; Reusch 2014). High-standing genetic variation is commonly found in phytoplankton populations (Medlin et al. 2000; Rynearson and Armbrust 2004; Iglesias-Rodríguez et al. 2006) and likely translates into phenotypic variability (Kremp et al. 2012; Schaum et al. 2012; Boyd et al. 2013). Phenotypic plasticity is the ability of a genotype to change its phenotype across environments (Bradshaw 1965) and can be assessed by the reaction norm of a particular trait (Boyd et al. 2013; Reusch 2014). When comparing reaction norms, a genotype-by-environment $(\mathrm{G}$ $X E$ ) interaction is evident when the phenotypic response of a genotype varies across environments or when distinct genotypes perform differently across these environmental conditions (De Jong 1990). In fact, such variation among genotypes within a population is the raw material for rapid adaptive evolution in the face of global change (Sgrò and Hoffmann 2004). Within a single trait, associated fitness cannot be maximized at all environmental conditions, which results in a trade-off (Agrawal et al. 2010). For 

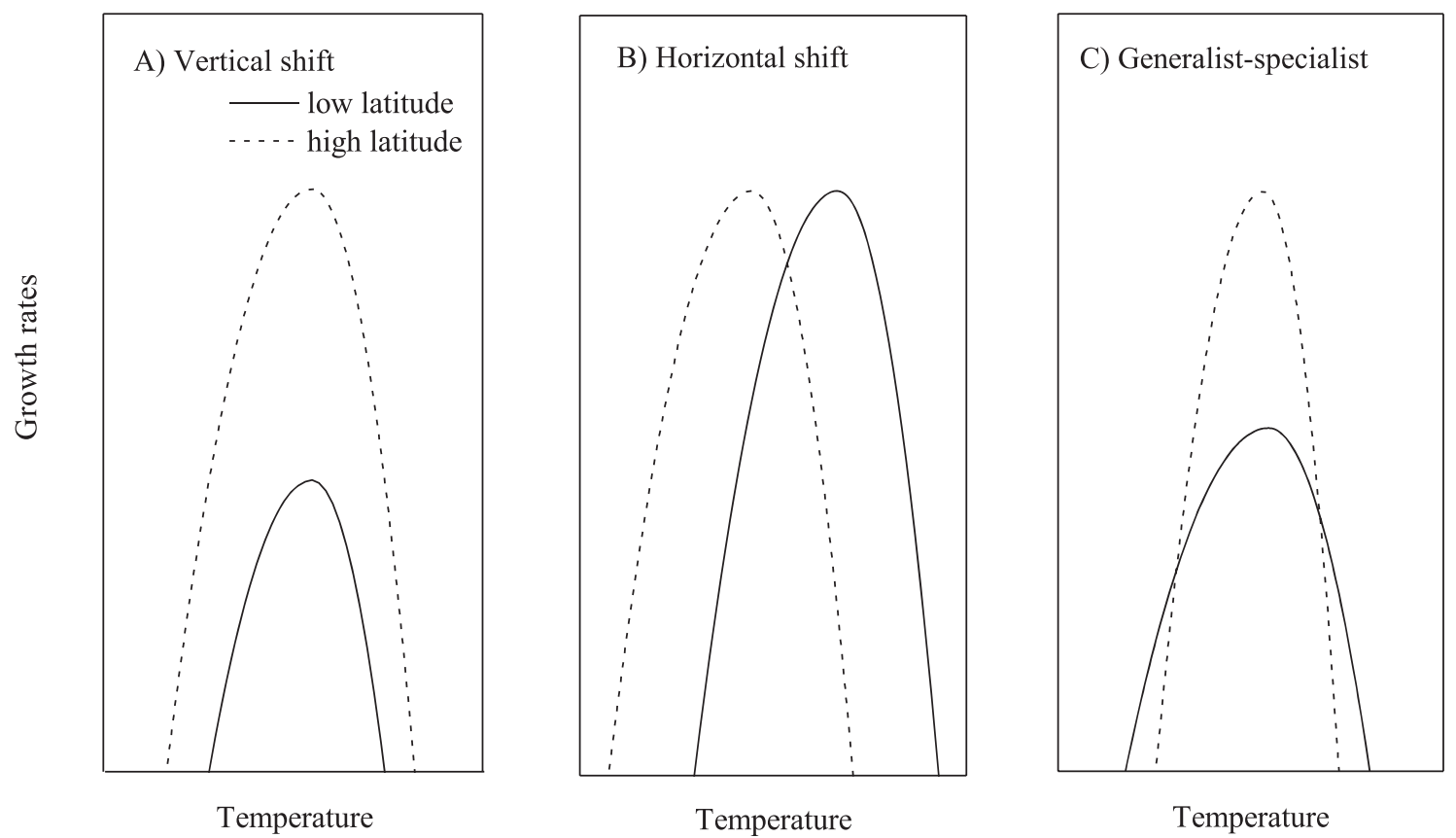

Fig. 1. Three theoretical models for variation in thermal reaction norms. (A) Vertical shift model, which represents variation in overall growth rates across all temperatures and vertical shift variation, is linear and totally explained by one principal component. (B) Horizontal shift model, which represents variation in the location of the maximum growth rates and horizontal shift variation, is nonlinear and not simply explained by one principal component. (C) Generalist-specialist model, which represents variation in the width of the growth rates curves and trade-off between width and maximal growth rates. Generalist-specialist variation is also nonlinear and totally explained by three principal components.

example, primary productivity often cannot be maximized at high and low temperatures at the same time, resulting in trade-offs in thermal tolerance (Gsell et al. 2012).

Thermal reaction norms in phytoplankton have been well studied, although often only a limited temperature range was covered (Thomas et al. 2012). Measuring the growth rates of $73 \mathrm{E}$. huxleyi isolates at $16^{\circ} \mathrm{C}$ and $26^{\circ} \mathrm{C}$, Brand (1982) concluded that low-latitude E. huxleyi populations are adapted to higher temperature and grow better at $26^{\circ} \mathrm{C}$ than those inhabiting the high-latitude regions. Optimum growth temperatures were found to be significantly lower for high-latitude than low-latitude $E$. huxleyi isolates (Conte et al. 1998). Buitenhuis et al. (2008) observed that E. huxleyi has a wider temperature range than three other coccolithophores, which may be related to its cosmopolitan distribution. However, different ocean regions may harbor locally adapted populations with genotypes that have very different temperature sensitivities. In order to address this question, we investigated whether variation in the physiological tolerance range between genotypes from different temperature regimes is larger than between distinct genotypes from the same location.

We assessed reaction norms over the entire temperature tolerance range using thermal performance curves (TPC), which describe the continuous phenotypic variation produced by a given isolate as a function of an environmental factor (Huey and Stevenson 1979). The common shape of a TPC is an increase in performance with increasing temperature until reaching a maximum, followed by a steep drop in performance (Huey and Stevenson 1979).
Huey and Kingsolver (1989) developed a model that decomposes the variation in thermal reaction norms into three modes of biological interest: performance as vertical shift ( $h$; Fig. 1A), optimal temperature as horizontal shift of maximal performance ( $m$; Fig. 1B), and generalistspecialist trade-off as width ( $w$; Fig. 1C). The template mode of variation (TMV) model not only decomposes the variation into predetermined modes of variation for a particular set of thermal performance curves but also quantifies the contributions of predicted modes of variation (Izem and Kingsolver 2005).

In this study, we compared E. huxleyi isolates from Bergen, Norway, and from the Azores, Portugal, at seven temperatures ranging from $8^{\circ} \mathrm{C}$ to $28^{\circ} \mathrm{C}$. Single-cell isolates were raised to monoclonal populations and verified by microsatellite markers and therefore in the following are referred to as genotypes. We applied the TMV model to estimate the relative importance of the three biological modes in differentiation between populations. Further, variations within populations were compared across measured temperatures. Neutral genetic markers were used to investigate gene flow between populations and population structure. Based on our results, a possible role of variation between and within natural E. huxleyi populations to cope with changing ocean conditions is discussed.

\section{Methods}

Cell isolation sites and culture conditions $-E$. huxleyi (Lohm.) Hay and Mohler (morphotype A) genotypes 96, 
Table 1. Sea surface temperatures (SST) for the Azores and Bergen.

\begin{tabular}{|c|c|c|c|c|c|}
\hline & Location & $\begin{array}{l}\text { Mean monthly } \mathrm{SST} \\
\text { range }\left({ }^{\circ} \mathrm{C}\right)\end{array}$ & $\begin{array}{l}\text { Minimum monthly } \\
\text { SST }\left({ }^{\circ} \mathrm{C}\right)\end{array}$ & $\begin{array}{l}\text { Maximum monthly } \\
\text { SST }\left({ }^{\circ} \mathrm{C}\right)\end{array}$ & References \\
\hline Azores & $\begin{array}{l}38^{\circ} 34^{\prime} \mathrm{N} \\
28^{\circ} 42^{\prime} \mathrm{W}\end{array}$ & $15.6-22.3$ & 12.6 & 32.9 & Wisshak et al. (2010) \\
\hline Bergen & $\begin{array}{l}60^{\circ} 18^{\prime} \mathrm{N} \\
05^{\circ} 15^{\prime} \mathrm{E}\end{array}$ & $6.0-16.0$ & -2 & 16.6 & $\begin{array}{l}\text { Samuelsen (1970); } \\
\text { Locarnini et al. (2006) }\end{array}$ \\
\hline
\end{tabular}

$85,75,73,63,62,51,42,41$, and 17 were isolated by K. T. Lohbeck from the Raunefjord, southwest of Bergen $\left(60^{\circ} 18^{\prime} \mathrm{N}, 05^{\circ} 15^{\prime} \mathrm{E}\right)$, in May 2009 , and E. huxleyi genotypes M23, M22, M21, M19, M17, M16, M13, M10, M8, and M7 were isolated by S. L. Eggers near Faial, at the Azores $\left(38^{\circ} 34^{\prime} \mathrm{N}, 28^{\circ} 42^{\prime} \mathrm{W}\right)$, in May or June 2010. Sea surface temperatures (SST) range from $6.0^{\circ} \mathrm{C}$ to $16.0^{\circ} \mathrm{C}$ off Bergen (Locarnini et al. 2006; Samuelsen 1970) and from $15.6^{\circ} \mathrm{C}$ to $22.3^{\circ} \mathrm{C}$ at the Azores (Wisshak et al. 2010; Table 1). Stock cultures were kept at $15^{\circ} \mathrm{C}$ in $50 \mathrm{~mL}$ tissue culture flasks (Sarstedt) with ventilation caps. The cultures were grown in monoclonal, nonaxenic populations. Regularly performed automated cell counts and microscopic inspections verified that no significant bacterial fraction was present.

Artificial seawater (ASW) was prepared according to Kester et al. (1967), but with the addition of $2380 \mu \mathrm{mol} \mathrm{kg-1}$ bicarbonate (Merck), resulting in initial concentrations of $2380 \mu \mathrm{mol} \mathrm{kg} \mathrm{kg}^{-1}$ total alkalinity (TA) and dissolved inorganic carbon (DIC) at a salinity of 35. ASW was enriched with $64 \mu \mathrm{mol} \mathrm{kg}-1$ nitrate $\left(\mathrm{NO}_{3}^{-}\right), 4 \mu \mathrm{mol} \mathrm{kg} \mathrm{kg}^{-1}$ phosphate $\left(\mathrm{PO}_{4}^{3-}\right), \mathrm{f} / 8$ concentrations for trace metals and vitamins (Guillard and Ryther 1962), $10 \mathrm{nmol} \mathrm{kg-1} \mathrm{SeO}_{2}$ (Danbara and Shiraiwa 1999), and $2 \mathrm{~mL} \mathrm{~kg}^{-1}$ of sterile filtered $(0.2 \mu \mathrm{m}$ pore size, Sartobran P 300, Sartorius) North Sea water to prevent possible trace metal limitation during culturing. Enriched ASW was aerated with sterile ambient air $(0.2 \mu \mathrm{m}$ pore size, Midisart 2000 PTFE, Sartorius) with about $40 \mathrm{~Pa}(\approx 400 \mu \mathrm{atm})$ partial pressure of $\mathrm{CO}_{2} \quad\left(\mathrm{P}_{\mathrm{CO}_{2}}\right)$ for $48 \mathrm{~h}$ at each temperature in a temperature-controlled incubation chamber (Rumed Rubarth Apparate $\mathrm{GmbH}$ ). The dry air was humidified with Mill-Q water before aeration of the ASW to minimize evaporation. A 10 liter polycarbonate bottle was covered with insulation foil to minimize temperature exchange during filling of the culture flasks at room temperature. After aeration, the ASW medium was sterilized by gentle pressure filtration $(0.2 \mu \mathrm{m}$ pore size, Sartobran P 300$)$ and carefully pumped into autoclaved $310 \mathrm{~mL}$ Duran square flasks (Schott). The flasks were filled with ASW medium leaving a minimum headspace of $\sim 1 \%$ to minimize gas exchange. The culture flasks were stored at treatment temperature until inoculation. Experimental cultures were kept in a RUMED Light Thermostat (Rubarth Apparate $\mathrm{GmbH})$ at a photon flux density of $160 \pm 5 \mu \mathrm{mol} \mathrm{m} \mathrm{m}^{-2} \mathrm{~s}^{-1}$ and a 16:8 light: dark cycle. Culture flasks were manually rotated twice a day at 5 and $12 \mathrm{~h}$ after the onset of the light phase to reduce sedimentation of the cells.

Experimental setup and procedures-For the temperature experiment, E. huxleyi genotypes 85, 75, 63, 62, 41, and 17 from Bergen and M23, M22, M21, M19, M13, and M10 from the Azores were grown at $8^{\circ} \mathrm{C}, 15^{\circ} \mathrm{C}, 18^{\circ} \mathrm{C}, 22^{\circ} \mathrm{C}$, $26^{\circ} \mathrm{C}, 27^{\circ} \mathrm{C}$, and $28^{\circ} \mathrm{C}$. Bergen genotype 75 was contaminated with a significant bacteria fraction and therefore excluded from the analysis. Genotypes sharing the same isolation site are referred to as a "population." Each genotype was grown in five replicates. Prior to the start of the experiment, genotypes were acclimated to the experimental conditions for six to eight generations at $15^{\circ} \mathrm{C}$ and thereafter for another six to eight generations at the target temperature, followed by the temperature assay.

Cell densities were assessed using a Z2 Coulter Particle Count and Size Analyzer (Beckman). Exponential growth rates $(\mu)$ were calculated for each replicate according to

$$
\mu=\left(\ln N_{1}-\ln N_{0}\right) / d
$$

where $N_{0}$ and $N_{1}$ are cell densities at the beginning and the end of a growth interval and $d$ is the duration of the growth period in days. A dilute batch cycle started with an initial inoculum of about 100,000 cells $\left(\sim 320\right.$ cells $\left.\mathrm{mL}^{-1}\right)$. To minimize changes in carbonate chemistry due to algal growth, cultures were transferred into the next dilute batch cycle before cell concentrations reached 100,000 cells $\mathrm{mL}^{-1}$. A maximum DIC drawdown of $9 \%$ was calculated based on final cell numbers and cellular carbon quotas of $E$. huxleyi (Bach et al. 2011). The duration of a batch cycle were 10 (Bergen) and 12 (Azores) $\mathrm{d}$ in the $8^{\circ} \mathrm{C}$ treatment; $5 \mathrm{~d}$ in the $15^{\circ} \mathrm{C}, 27^{\circ} \mathrm{C}$, and $28^{\circ} \mathrm{C}$ treatments; $3 \mathrm{~d}$ in the $22^{\circ} \mathrm{C}$ treatment; and $4 \mathrm{~d}$ in the $18^{\circ} \mathrm{C}$ and $26^{\circ} \mathrm{C}$ treatments. $E$. huxleyi genotype 17 was cultured $11 \mathrm{~d}$ at $27^{\circ} \mathrm{C}$ due to slow growth rates.

Carbonate chemistry sampling and measurements-Before inoculation, DIC samples were taken from culture media of each dilute batch cycle and were measured by an infrared $\mathrm{CO}_{2}$ analyzer system (Automated Infra Red Inorganic Carbon Analyzer, Marianda). TA was measured from all treatments by open-cell potentiometric titration using a Metrohm Basic Titrino 794 according to Dickson et al. (2003). DIC and TA measurements were used to calculate $\mathrm{CO}_{2}$ partial pressure in the ASW using the $\mathrm{CO}_{2}$ System Calculations in MS Excel software (Lewis and Wallace 1998). Calculated $\mathrm{P}_{\mathrm{CO}_{2}}$ and $\mathrm{pH}$ (on the total scale) were on average $45.3 \pm 6.1 \mathrm{~Pa}$ and $8.007 \pm 0.051$, respectively.

$T M V$ - Growth rates of each E. huxleyi genotype were predicted to show a thermal performance curve (TPC) shape along the temperature gradient. We used the TMV approach from Izem and Kingsolver (2005) to decompose the variation of growth rates into modes of biological 
interest. The TMV model fits a common shape $z(t)$ for the growth rates over all data points (Fig. 1). We evaluated the fit of the predetermined common shape to the growth rates by rescaling the growth rates with respect to parameter estimates $(h, m, w)$ for each genotype.

The first criterion was continuity, which can be described as

$$
z_{i, j}=z_{i}\left(t_{j}\right)+\varepsilon_{i, j} ; j \in\{1, \ldots, J\}, i \in\{1, \ldots, I\}
$$

where $t_{j}$ is the $j$ th temperature $t, i$ is the number of genotypes, and $\varepsilon_{i, j}$ represents technical or experimental errors. In the function (2), $J$ is the number of the investigated temperatures, and $I$ is the number of the investigated genotypes. In this study, $J=7$ and $I=11$. Then the common shape $z(t)$ for the TPC was generated using the following model with three parameters:

$$
z_{i}=h_{i}+\frac{1}{w_{i}} z\left[\frac{1}{w_{i}}\left(t-m_{i}\right)\right]
$$

where $z_{i}$ is the common template shape of the curves for all genotypes. For each genotype $i$, the parameter $h_{i}$ is the average growth rate, $m_{i}$ is the optimum temperature, and $w_{i}$ is the width and describes the generalist-specialist mode of variation. The common template shape $z(t)$ can be fitted using a polynomial of any degree. Since a polynomial of higher degree generally fits the data better, we chose to use the fourth-order polynomial, which also minimized the sum of squared errors. For further details, see Izem and Kingsolver (2005). Note that height $h_{i}$ as defined here indicates the overall or "average" growth rates across all temperatures, not just the maximum growth rates at the optimal temperature. The maximum growth rate at the optimal temperature for each curve was obtained by the equation

$$
z_{\max }=h_{i}+z(0) \frac{1}{w_{i}}
$$

Data analyses-Parameters $h, m$, and $w$ were calculated using Matrix Laboratory (MATLAB 7. 14, The MathWorks), and the scripts were provided by Izem and Kingsolver (2005). Statistical analyses were performed using $\mathrm{R}$ (version 2.15.2). The mean growth rate of five replicates and temperature were used to fit the growth rate curve and calculate $h, m$, and $w$ for each genotype. A twoway ANOVA was conducted to examine the effect of population, temperature, and their interactions on growth rates. A one-way ANOVA was performed to test the statistical significance in $h, m$, and $w$ between the Bergen and the Azores populations with "population" as predictor, and $h, m$, or $w$ as response variable. A Tukey post hoc test was used to test for the genotype differentiation within a population when the ANOVA was significant. An $F$-test was used to test for variance differences between and within the populations. Further, a Levene test was conducted to test for homogeneity of variances in case of significant data, and a generalized least squares model was used to stabilize heterogeneity if variances were inhomogeneous. Normality was tested with a Shapiro-Wilk test.
Microsatellite genotyping-To test for neutral genetic variation between genotypes of the same and different origin, we used microsatellite genotyping with E. huxleyi specific primers (Iglesias-Rodríguez et al. 2006). Ten primers were tested, of which five primers-EHMS15, EHMS37, P02B12, P02F11, and P02E09—could be applied with reproducible results and variable alleles between populations and genotypes. Note that all 10 genotypes from each population were used for the microsatellite analysis. However, only six genotypes per population were chosen for the temperature experiment due to limited space in the climate chambers. For deoxyribonucleic acid (DNA) extraction, cells were filtered onto Cyclopore track-etched polycarbonate filters $(0.8 \mu \mathrm{m}$ pore size, Whatman). The filters were washed with $500 \mu \mathrm{L}$ freshly sterile filtered ASW, and the cell suspension was transferred into Eppendorf tubes, which were centrifuged (5424 Centrifuge) for $10 \mathrm{~min}$ at 2348 relative centrifugal force. The supernatant was discarded, and the cell pellet was stored at $-20^{\circ} \mathrm{C}$. DNA was extracted using an Invisorb Spin Tissue Minikit (Invitek) according to the manufacturer's protocol. DNA concentration was measured with a Nanodrop spectrophotometer (Thermo Scientific). Microsatellite loci were amplified with the Dream Taq polymerase (Thermo Scientific) using $1 \mu \mathrm{L}$ forward and reverse 6-carboxyfluorescein (Fam)- and hexachlorofluoresceine (Hex)-labeled primers per $10 \mu \mathrm{L}$ reaction. The polymerase chain reaction (PCR) conditions were 3 min denaturation at $94^{\circ} \mathrm{C}$, followed by 27 cycles of denaturation at $94^{\circ} \mathrm{C}$, a primer-specific annealing temperature (see Table 2), and an elongation at $72^{\circ} \mathrm{C}$ for $1 \mathrm{~min}$ each step and a final elongation of $10 \mathrm{~min}$ at $72^{\circ} \mathrm{C}$. One microliter of the PCR product was used for fragment length analysis on an Applied Biosystems 3130xL automated sequencer. Allele sizes were called automatically and afterward manually checked using GeneMarker version 1.85 (SoftGenetics LLC) against the size standard Rox350 (Applied Biosystems).

Genetic differentiation analysis-Allele frequencies, observed $\left(\mathrm{H}_{\mathrm{o}}\right)$ and expected $\left(\mathrm{H}_{\mathrm{e}}\right)$ heterozygosity, and deviation from the Hardy-Weinberg equilibrium (HWE) for each locus were calculated using the software Arlequin version 3.5 (Excoffier et al. 2005). Further, Wright's Fixation Index $\left(\mathrm{F}_{\mathrm{ST}}\right)$ was used to assess population structure with the software Arlequin version 3.5 (Wright

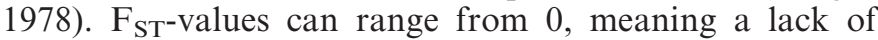
differentiation, to 1, meaning that compared groups are distinct. Values of 0.05 show little genetic differentiation, $0.05-0.15$ moderate genetic differentiation, $0.15-0.25$ large genetic differentiation, and finally $>0.25$ very large genetic differentiation (Wright 1978). The microsatellite data were analyzed for null alleles using the software Microchecker version 2.2.3 (van Oosterhout et al. 2004), with null allele frequencies tested by the method of Brookfield (1996). To detect the structure of the "populations" without any a priori assumptions, the Bayesian clustering algorithm implemented in Structure version 2.3.3 was applied to detect potential structuring among genotypes (Pritchard et al. 2000). A genetic admixture model was used with a burn-in period of 10,000 
Table 2. Applied microsatellite primers for E. huxleyi (Iglesias-Rodríguez et al. 2006). Last column gives the optimized annealing temperatures used for PCR amplification. EMBL, European Molecular Biology Laboratory.

\begin{tabular}{|c|c|c|c|c|}
\hline Locus & Primer sequence & $\begin{array}{c}\text { EMBL accession } \\
\text { number }\end{array}$ & $\begin{array}{l}\text { Sequenced repeat } \\
\text { motif }\end{array}$ & $\begin{array}{c}\text { Annealing temperature } \\
\text { PCR }\left({ }^{\circ} \mathrm{C}\right)\end{array}$ \\
\hline \multirow[t]{2}{*}{ EHMS15 } & F: TCGAGGCGCGTCACACAC & AJ487304 & (GT)27GC & 54 \\
\hline & R: GCGAGCGGTGGGCAATGT & AJ487305 & (GT) 9 & \\
\hline \multirow[t]{2}{*}{ EHMS37 } & F: TGTGAGAGTGAGCACGCA & AJ494737 & (GT)23 & 60 \\
\hline & R: TTGAGGAGGATTACGAGGTC & AJ494738 & & \\
\hline \multirow[t]{2}{*}{$\mathrm{P} 02 \mathrm{~B} 12$} & F: GGTTAATCGCAGCAAAGAGC & AJ487309 & $(\mathrm{GT}) 10$ & 58 \\
\hline & R: CAGTCTTGATCGGGAACGA & AJ487311 & & \\
\hline \multirow[t]{2}{*}{ P02F11 } & F: CTCGTGTGGCTATGCCTATG & AJ487316 & $(\mathrm{GT}) 11$ & 58 \\
\hline & R: TCCAAGAGCAAAGTGCAAAA & AJ487317 & & \\
\hline \multirow[t]{2}{*}{ P02E09 } & F: ACTCGGACTGGACGCACA & AJ494741 & $(\mathrm{GT}) 9$ & 60 \\
\hline & R: GGCTGCTCTTCCCCTCTCTA & AJ494742 & & \\
\hline
\end{tabular}

reiterations and 100,000 Markov chain Monte Carlo iterations under default settings with number of clusters $(\mathrm{K})$ varying from one to five. In order to detect the most likely number of genetic clusters, the post hoc function $\Delta \mathrm{K}$ after Evanno et al. (2005) was used.

\section{Results}

Genetic structure-For the 10 analyzed isolates per population, the number of alleles varied between two and nine. A higher number of alleles among all loci were found in the Azores population compared to the Bergen population (Table 3). Heterozygote deficiencies were found in two of five tested loci in the Azores population (Markov chain method, $p<0.05$ ). Table 3 gives $\mathrm{H}_{\mathrm{o}}$ and $\mathrm{H}_{\mathrm{e}}$ heterozygosities for both populations at each locus. $\mathrm{H}_{\mathrm{e}}$ ranged from 0.19 to 0.92 and $H_{o}$ varied between 0 and 1 . In the Azores population, $\mathrm{H}_{\mathrm{o}}$ varied between 0.22 and 0.89 and revealed heterozygote deficiencies at two of five loci tested. Evidence for null alleles was found in loci P02B12 and EHMS37. In the Bergen group, $\mathrm{H}_{\mathrm{o}}$ varied between 0 and 1, and no deviation from the HWE was detected. Pairwise comparison revealed a significant population differentiation with an $\mathrm{F}_{\mathrm{ST}}$ of $0.148(p<0.01)$. This complies with a moderate to strong genetic differentiation according to Wright (1978). Note that for the temperature experiment, only six genotypes per population were used, whereas the microsatellite analysis included four additional genotypes per population from stock cultures maintained at the GEOMAR Helmholtz-Centre for Ocean Research, Kiel, Germany. The structure analysis revealed a most likely number of genetic clusters of $\mathrm{K}=2$; thus, two distinct groups could be detected.

Between-population variation in growth rates-There was a temperature- and temperature versus population interaction-effect on growth rates (two-way ANOVA, $F_{6}=511.34$ for temperature treatments, $F_{6}=33.10$ for interaction, both $p<0.001$ ). Growth rates of E. huxleyi genotypes in both populations initially increased with increasing temperature, reached a maximum, and then declined with further temperature increase (Fig. 2). The Bergen population grew faster at $8^{\circ} \mathrm{C}$ (ANOVA, $F_{1}=25.89, p<0.001$ ) and failed to grow at $28^{\circ} \mathrm{C}$. The Azores population grew slightly faster at $26^{\circ} \mathrm{C}$ and $27^{\circ} \mathrm{C}$ (ANOVA, $F_{1}=1.379$ for $26^{\circ} \mathrm{C}$ treatment, $F_{1}=0.481$ for $27^{\circ} \mathrm{C}$ treatment, both $p>$ $0.05)$ and can still grow at $28^{\circ} \mathrm{C}$.

Values of $h$ (overall performance across all temperatures) were estimated to be -0.038 to $0.031 \mathrm{~d}^{-1}$ for the Azores population and -0.083 to $0.084 \mathrm{~d}^{-1}$ for the Bergen population. There was no difference in $h$ between the populations (ANOVA, $F_{1}=0.028, p=0.872$; Fig. 3A; Table 4). Estimated optimum temperatures $m$ were higher in the Azores population with $23.4^{\circ} \mathrm{C}$ to $24.7^{\circ} \mathrm{C}$, in comparison to the Bergen population with $22.5^{\circ} \mathrm{C}$ to $23.0^{\circ} \mathrm{C}$ (ANOVA, $F_{1}=22.69, p<0.005$; Figs. 2C, 3B). Optimum growth rates $z_{\max }$ were 1.539 to $1.614 \mathrm{~d}^{-1}$ for the Azores population and 1.554 to $1.763 \mathrm{~d}^{-1}$ for the Bergen population. Statistical comparison of optimum growth rates between the Bergen and the Azores populations failed significance. This may be attributed to a lack of sufficient statistical power to detect differences with the

Table 3. Observed $\left(\mathrm{H}_{\mathrm{o}}\right)$ and expected $\left(\mathrm{H}_{\mathrm{e}}\right)$ heterozygosities for the Azores and the Bergen population, test for Hardy-Weinberg equilibrium, and number of alleles at each locus. Number of permutations: 10,000; number of steps in Markov chain: 1,000,000; number of dememorization steps: 100,000 . Asterisks indicate significances when $p \leq 0.05$.

\begin{tabular}{|c|c|c|c|c|c|c|c|c|}
\hline \multirow[b]{2}{*}{ Locus } & \multicolumn{4}{|c|}{ Azores } & \multicolumn{4}{|c|}{ Bergen } \\
\hline & $\mathrm{H}_{\mathrm{o}}$ & $\mathrm{H}_{\mathrm{e}}$ & $p$ & Number of alleles & $\mathrm{H}_{\mathrm{o}}$ & $\mathrm{H}_{\mathrm{e}}$ & $p$ & Number of alleles \\
\hline E9 & 0.88889 & 0.83660 & 0.12110 & 7 & 1.00000 & 0.85263 & 0.27180 & 9 \\
\hline B12 & 0.44444 & 0.62092 & $0.01388 *$ & 5 & 0.00000 & 0.18947 & 0.05237 & 2 \\
\hline $\mathrm{F} 11$ & 0.66667 & 0.84314 & 0.06832 & 7 & 0.50000 & 0.39474 & 1.00000 & 2 \\
\hline S37 & 0.77778 & 0.92157 & $0.02004 *$ & 9 & 0.70000 & 0.76316 & 0.26366 & 6 \\
\hline S15 & 0.22222 & 0.20915 & 1.00000 & 2 & 0.77778 & 0.50327 & 0.17651 & 2 \\
\hline
\end{tabular}



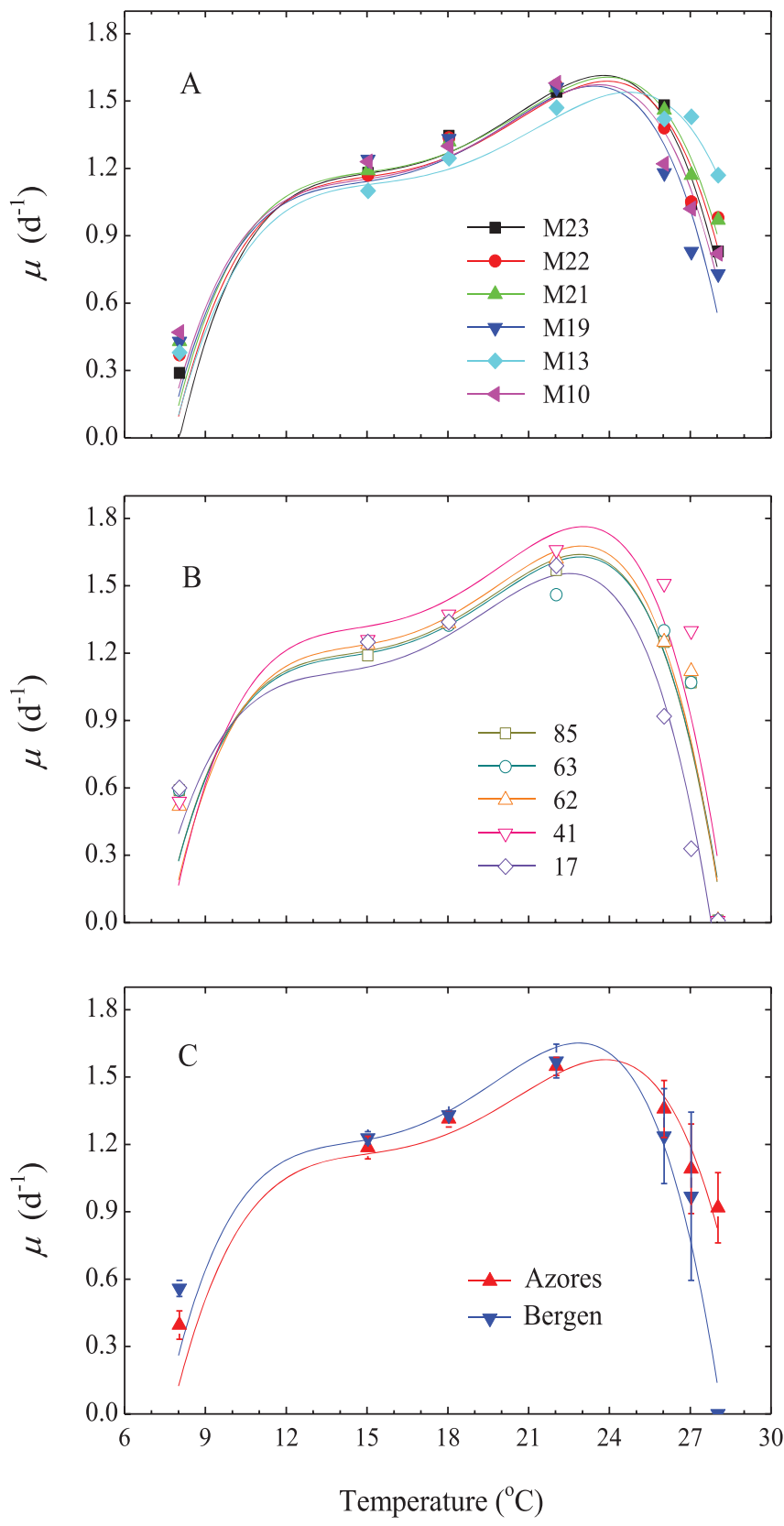

Fig. 2. Thermal reaction norms for growth rates of $E$. huxleyi genotypes. (A) Fitted growth rate curves of individual genotypes from the Azores. (B) Fitted growth rate curves of individual genotypes from Bergen. (C) Fitted growth rate curves for the Azores and the Bergen populations. The curves in panels A and B are fitted using function (3) based on mean growth rates of five replicates. The curves in panel $\mathrm{C}$ are fitted using function (3) based on average growth rates of six genotypes from the Azores and five genotypes from Bergen.

small sample size we used (ANOVA, $F_{1}=4.618, p=$ 0.060 ; Fig. 3D). Values of $w$ were remarkably larger for the Azores population with 1.034 to 1.109 than those for the Bergen population with 0.997 to 1.023 (ANOVA, $F_{1}$ $=15.41, p<0.005$; Figs. 2C, 3C). Larger $m$ was correlated with larger $w$ and $h$ but with lower $z_{\max }$ for all genotypes.
The TMV model explains more than $67 \%$ of the total variation in the data. A major biological result is that the horizontal shift mode accounts for the largest component of variation (45\%). Generalist-specialist (18\%) and vertical shift (4\%) explain smaller fractions of the total variation in the data.

Within-population variation in growth rates-The continuous reaction norms of each genotype of the Azores and Bergen populations are shown in Fig. 2A,B. All genotypes grew at similar rates in the Bergen population between $8^{\circ} \mathrm{C}$ and $18^{\circ} \mathrm{C}$ and in the Azores population between $8^{\circ} \mathrm{C}$ and $22^{\circ} \mathrm{C}$. Based on the local temperatures at the Azores and Bergen, we chose three temperatures $\left(8^{\circ} \mathrm{C}, 22^{\circ} \mathrm{C}\right.$, and $\left.27^{\circ} \mathrm{C}\right)$ and computed the correlations among growth rates between $8^{\circ} \mathrm{C}$ and $22^{\circ} \mathrm{C}, 22^{\circ} \mathrm{C}$ and $27^{\circ} \mathrm{C}$, and $8^{\circ} \mathrm{C}$ and $27^{\circ} \mathrm{C}$ (Fig. 4). We found a positive trend in the correlation among growth rates between $8^{\circ} \mathrm{C}$ and $22^{\circ} \mathrm{C}$ and a negative trend between $22^{\circ} \mathrm{C}$ and $27^{\circ} \mathrm{C}$ for the Azores population. For the Bergen population, we found a negative trend in the correlation among growth rates between $8^{\circ} \mathrm{C}$ and $22^{\circ} \mathrm{C}$ and a positive trend between $22^{\circ} \mathrm{C}$ and $27^{\circ} \mathrm{C}$. Negative trends in correlations among growth rates between $8^{\circ} \mathrm{C}$ and $27^{\circ} \mathrm{C}$ were found in both populations. However, all correlations failed statistical significance. Thermal reaction norms for growth rates showed that E. huxleyi genotypes, which at higher temperatures had higher growth rates compared to other genotypes of the same population, performed worse at lower temperatures and vice versa. There was no genotype that performed best across all temperatures (Fig. 2A,B; Table 4).

In the TMV model, $m$ was positively correlated with $w$ and $h$ but negatively correlated with $z_{\max }$ in the Azores population. These correlations among $m, h, w$, and $z_{\max }$ are similar for all genotypes. Larger $m$ was correlated with lower $w$ and $h$ but with larger $z_{\max }$ in the Bergen population. In most cases, correlations among $m, h, w$, and $z_{\max }$ in the Bergen population showed opposite trends for all genotypes. These results may be due to a greater contribution of the Azores genotypes to whole genotypes in correlations among $m, h, w$, and $z_{\max }$ or more genotypes used in the Azores population.

The within-population variations remained low over a range of temperatures from $15^{\circ} \mathrm{C}$ to $22^{\circ} \mathrm{C}$ and then rapidly increased at higher temperatures (Fig. 5). Variations at $26^{\circ} \mathrm{C}, 27^{\circ} \mathrm{C}$, or $28^{\circ} \mathrm{C}$ were significantly higher than those at $22^{\circ} \mathrm{C}$ ( $F$-test, $\left.p<0.05\right)$. Normalized standard deviations in growth rates were higher in the Azores population at $8^{\circ} \mathrm{C}$, $15^{\circ} \mathrm{C}$, and $18^{\circ} \mathrm{C}$ compared to the Bergen population, while we observed the opposite trend at $22^{\circ} \mathrm{C}, 26^{\circ} \mathrm{C}$, and $27^{\circ} \mathrm{C}$ (Fig. 5). Normalized standard deviations for growth rates of all $11 \mathrm{E}$. huxleyi genotypes were only higher at $8^{\circ} \mathrm{C}$ and $28^{\circ} \mathrm{C}$, while at $15^{\circ} \mathrm{C}, 18^{\circ} \mathrm{C}, 22^{\circ} \mathrm{C}, 26^{\circ} \mathrm{C}$, and $27^{\circ} \mathrm{C}$, they were more or less the same as the normalized standard deviations for growth rates of five (Bergen) or six (Azores) genotypes. In summary, within-population variation in growth rates increased with increasing temperatures above $22^{\circ} \mathrm{C}$, while between-population variation in growth rates was higher than within-population variation at both ends of the temperature range tested. 

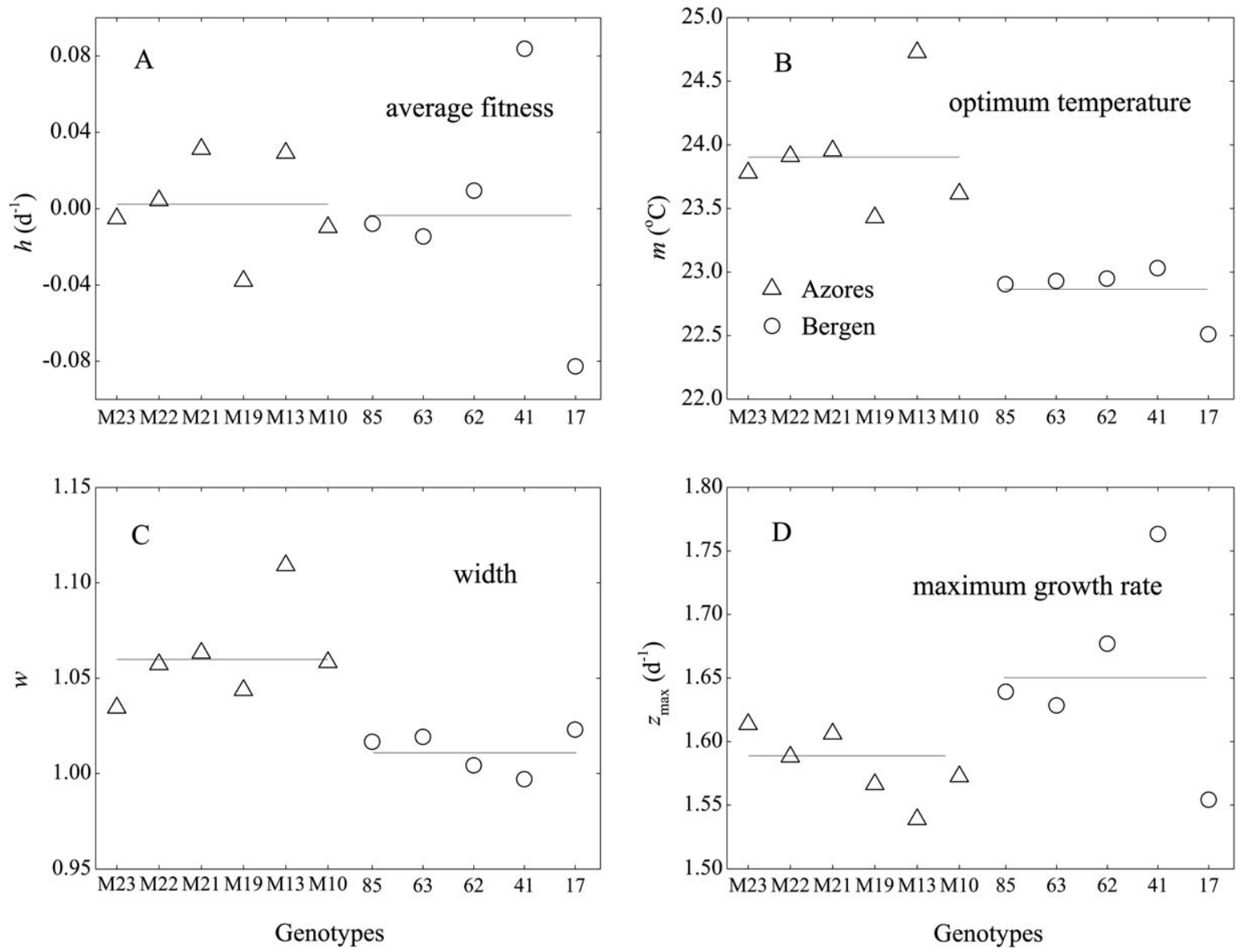

Fig. 3. Fitted parameters for growth rates of E. huxleyi genotypes from the Azores and Bergen. (A) Height parameter (h), (B) location parameter $(m),(\mathrm{C})$ width parameter $(w)$, and $(\mathrm{D})$ maximum growth rate $\left(z_{\text {max }}\right)$. Lines in each panel represent the average values of $h, m, w$, and $z_{\max }$ for the Azores and the Bergen populations. Data were calculated using functions (3) and (4) based on mean growth rates of five replicates.

\section{Discussion}

Population structure-Microsatellite markers were used to assess the differentiation between the Bergen and the Azores populations. We found genetic differentiation between these populations, which suggests limited gene flow and potential for local adaptation (Leducq et al 2014). Based on our microsatellite analysis, two clearly separated genetic clusters were detected, corresponding to the geographical origin of the genotypes. This supports the interpretation from Iglesias-Rodríguez et al. (2006), who suggested that the genetic differentiation, based on the $\mathrm{F}_{\mathrm{ST}}$

Table 4. Growth rate $(\mu)$, height parameter $(h)$, location parameter $(m)$, width parameter $(w)$, and maximum growth rate $\left(z_{\text {max }}\right)$ of individual $E$. huxleyi genotype; $\mu$ is calculated using function (1); $h, m$, and $w$ function (3); and $z_{\max }$ function (4). See text for details about calculations of all parameters.

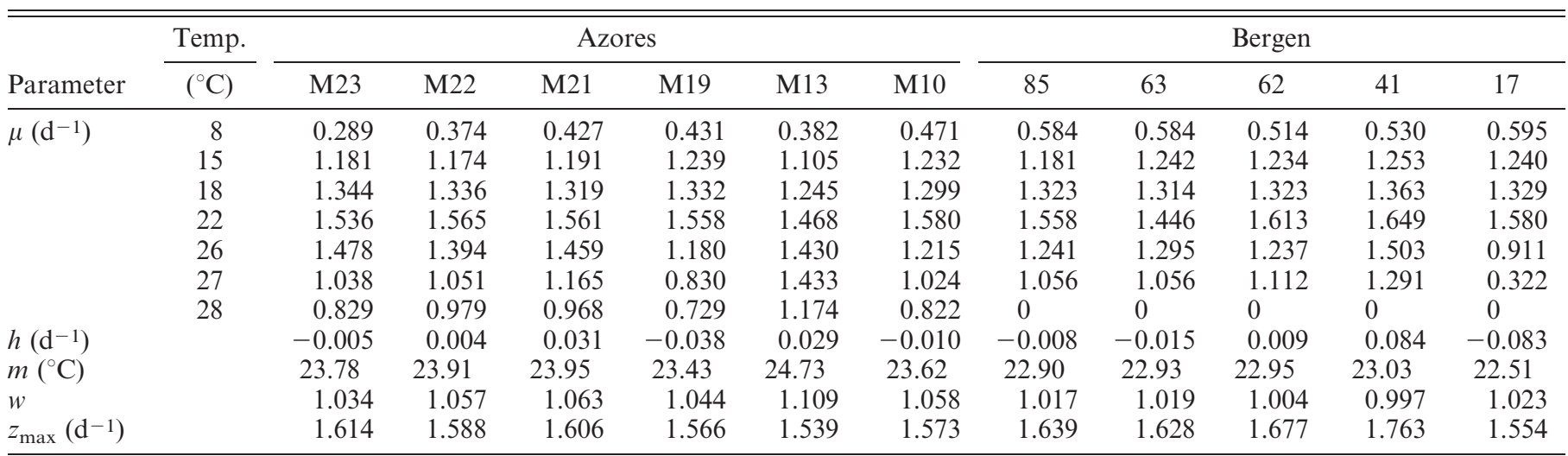



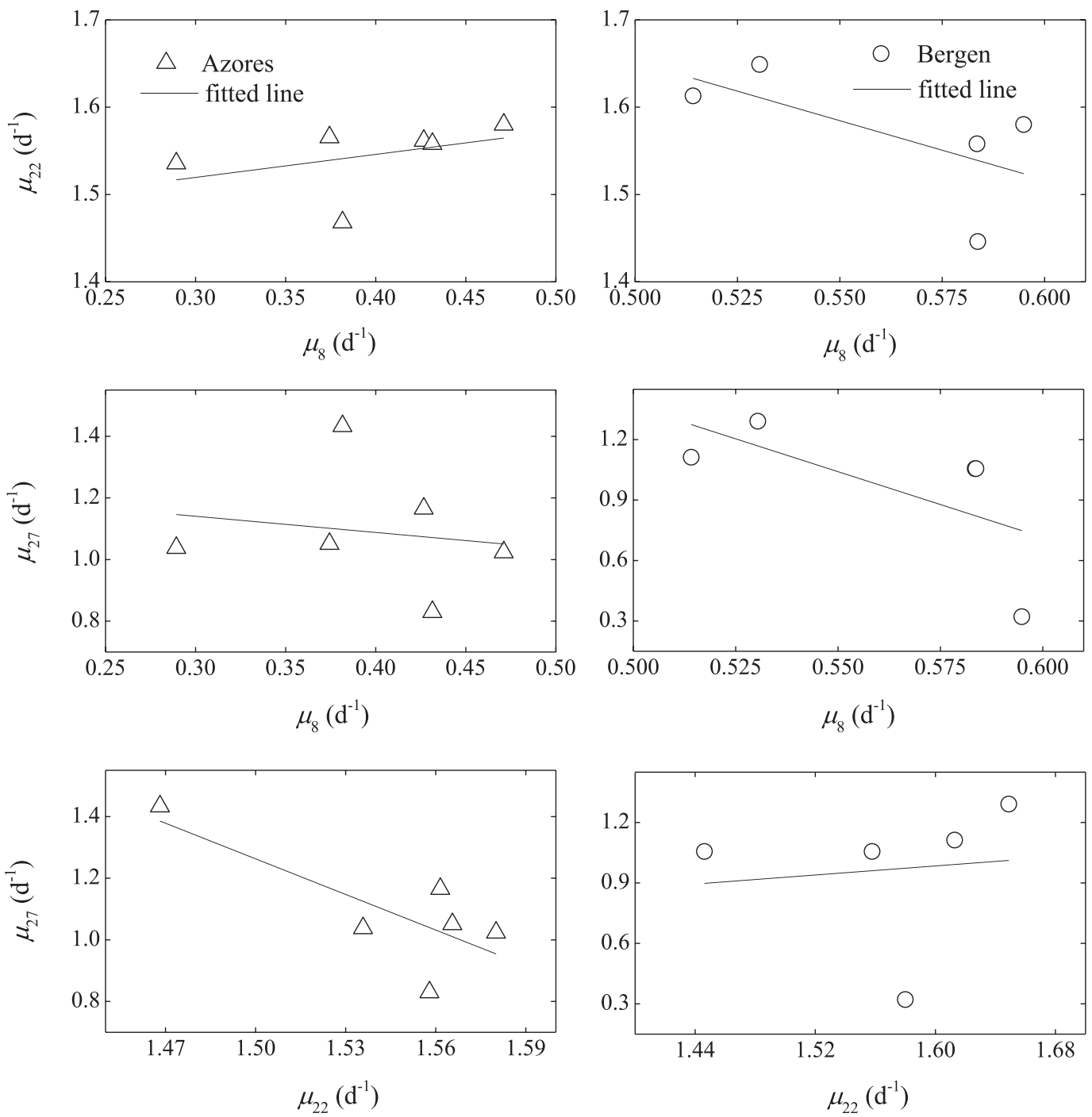

Fig. 4. Correlations among growth rates between $8^{\circ} \mathrm{C}$ and $22^{\circ} \mathrm{C}, 22^{\circ} \mathrm{C}$ and $27^{\circ} \mathrm{C}$, and $8^{\circ} \mathrm{C}$ and $27^{\circ} \mathrm{C}$. Solid lines were fitted linearly based on growth rates of six genotypes from the Azores and five genotypes from Bergen; $\mu_{8}, \mu_{22}$, and $\mu_{27}$ are the growth rates of each genotype at $8^{\circ} \mathrm{C}, 22^{\circ} \mathrm{C}$, and $27^{\circ} \mathrm{C}$, respectively.

they found, may indicate selection of different genotypes due to different environmental conditions and restricted gene flow across biogeographic provinces through barriers caused by current systems. Cook et al. (2013) also found significant genetic differentiation among $E$. huxleyi populations from seven sites south off Australia. These findings fit well to the results from a recent $E$. huxleyi genome study that reported large genomic differences between genotypes from different ocean regions (Read et al. 2013) and support the presence of biogeographic structuring in marine phytoplankton.

Between-population variation-Thermal reaction norms are a useful tool to describe the thermal adaptation of organisms (Conte et al. 1998). Here we applied the TMV model to investigate thermal reaction norms in E. huxleyi over the entire naturally encountered temperature range. Note that the TMV approach enables us to compare difference in the parameters $h, m$, and $w$ between populations. However, these parameters do not necessarily represent the real growth rates, optimum temperatures for growth, or temperature niche widths of the genotypes. In this study, we chose to use the TMV model with the fourthorder polynomial degree (Fig. 2). This function has two vertex points that do not reflect any biological response. Rather, it is considered a statistical tool to investigate the continuous thermal reaction norms.

The TMV analysis revealed a significantly higher optimum growth temperature for the Azores than for the Bergen populations (Fig. 2), which is in agreement with the respective temperature regime at the geographical origin of each population. These results are in line with findings from this and other phytoplankton species that thrive in habitats characterized by distinct thermal regimes (Conte et al. 1998; Kremp et al. 2012; Flombaum et al. 2013).

Interestingly, the TMV analysis suggested a broader temperature niche for the Azores population (Fig. 3C) despite their occurrence in a narrower mean monthly SST 
Within and between population variation in growth rates

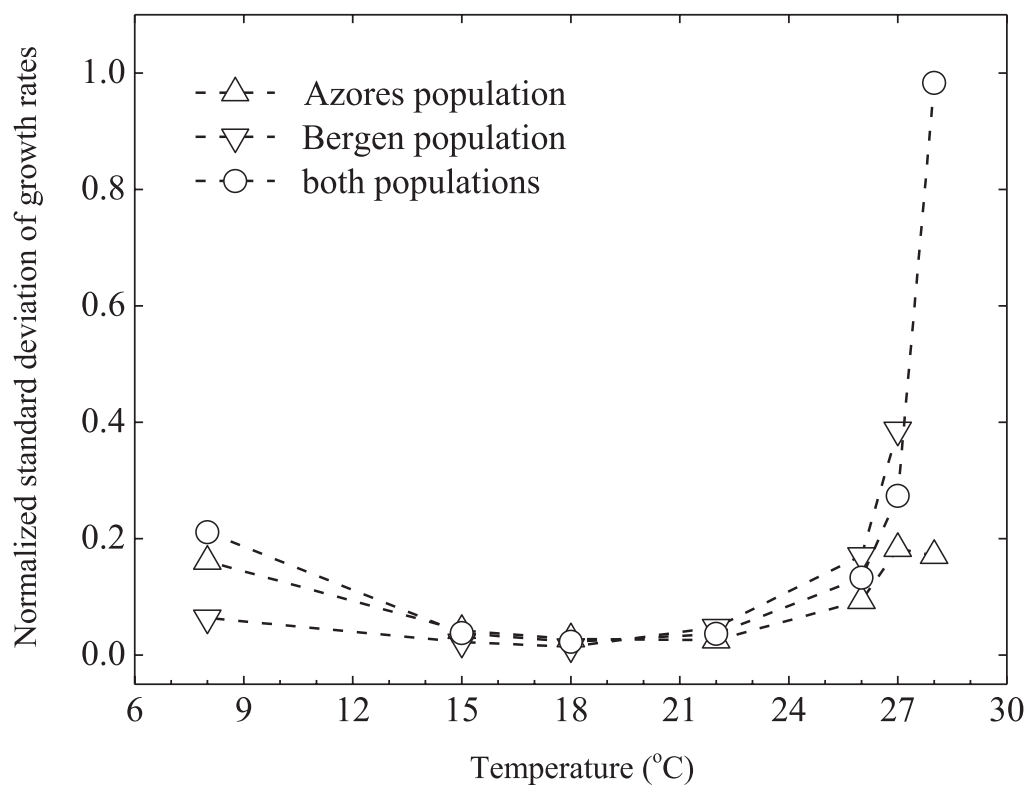

Fig. 5. Within-population variation in growth rates compared with between-population variation in growth rates. Data are calculated based on growth rates of six genotypes in the Azores population and five genotypes in the Bergen population and 11 genotypes in both populations. Normalized standard deviation is calculated as the ratio of the standard deviation to absolute growth rates.

range in lower-latitude waters (Table 1). This result may indicate that temperature niche width cannot be easily predicted based on the geographic origin of a phytoplankton population. The Bergen genotypes failed to grow at $28^{\circ} \mathrm{C}$, while we were not able to investigate the lower extreme temperatures. Growth rate differences at $8^{\circ} \mathrm{C}$ suggest that the Bergen population will probably have a lower minimum growth temperature than the Azores population. Consequently, we may have underestimated the niche width of the Bergen population.

Optimum temperatures for growth are commonly reported to be considerably higher than annual mean temperatures at their origin for isolates from polar and temperate waters. By contrast, isolates from tropical water are usually closer to the annual mean temperatures found at the sites where they were isolated (Thomas et al. 2012). This pattern also applies to the Bergen genotypes, which displayed considerably higher optimum growth temperatures than the maximum SST at their sampling location. The temperature for maximal growth rates of $E$. huxleyi cultures commonly found under laboratory conditions is considerably higher than the temperatures at which those populations usually predominate in the field (Conte et al. 1998; Buitenhuis et al. 2008). This discrepancy may be explained by the artificial laboratory environment, which differs from the much more complex and variable natural environment. Growth rates were measured during the exponential growth period of individual genotypes, which were cultured under nutrient-replete conditions in our study. Optimal growth of E. huxleyi populations in Norwegian fjords typically occurs during May-July (Fernández et al. 1996). At this time, surface water temperatures range from about $8^{\circ} \mathrm{C}$ to $14^{\circ} \mathrm{C}$ (Locarnini et al. 2006), and growth is most likely controlled primarily by optimal nutrient and light availability (Fernández et al. 1996).

Within-population variation - In the present study, we applied continuous thermal reaction norms (Fig. 2A,B) to investigate plasticity and $\mathrm{G} \times \mathrm{E}$ interactions among clonal isolates from each population (Gsell et al. 2012). $\mathrm{G} \times \mathrm{E}$ interactions were identified by different slopes in the thermal reaction norms of individual genotypes within both populations (Fig. 2A,B). Variation in growth rates was most pronounced in the physiologically more demanding temperature ranges. The presence of ample phenotypic variability among isolates from natural populations has also been reported for other phytoplankton species (Kremp et al. 2012; Schaum et al. 2012) and fits well to the highstanding genetic variation commonly found in marine phytoplankton populations (Medlin et al. 2000; Rynearson and Armbrust 2004; Iglesias-Rodríguez et al. 2006). High genetic variation within populations suggests that rapid evolutionary adaptation by genotypic selection may have the potential to mitigate detrimental effects of global change (Lohbeck et al. 2012; Reusch 2014).

Reaction norms can be used to identify trade-offs in particular traits. For example, genotypes that show high growth rates in one treatment may grow worse in the other treatment (Agrawal et al. 2010). Trade-offs in fitness relevant traits are potentially important in maintaining genetic diversity within populations. For example, Gsell et al. (2012) compared reaction norms of different genotypes of the diatom Asterionella formosa from two different habitats and did not find a genotype that performed best at all temperatures. In order to test for trade-offs, we performed a correlation analysis using growth rates at 
$8^{\circ} \mathrm{C}, 22^{\circ} \mathrm{C}$, and $27^{\circ} \mathrm{C}$ (Fig. 4). However, we were not able to detect any statistical significant correlations, probably because the sample size we used was too small to gain sufficient statistical test power.

Brand (1982) observed differences in growth rates when he exposed E. huxleyi isolates from different parts of the ocean to different temperatures already more than $30 \mathrm{yr}$ ago. However, the importance of standing genetic variation in natural phytoplankton populations to cope with rapid environmental changes is only slowly being recognized (Kremp et al. 2012; Schaum et al. 2012; Reusch and Boyd 2013).

In this study, we have demonstrated neutral genetic and phenotypic variability within and between two E. huxleyi populations from the cool North Atlantic waters off Bergen and the warm central Atlantic waters at the Azores. Our findings provide supporting evidence that biogeographic structuring and local adaptation are common in populations of the widely distributed coccolithophore E. huxleyi. Variations in thermal reaction norms of different genotypes emphasize the difficulty in predicting ecological dynamics in future ocean scenarios from studying a single contemporary genotype (Kremp et al. 2012; Schaum et al. 2012; Boyd et al. 2013). Future research should therefore use multiple genotypes from various locations and also strengthen the focus on community-level experiments. High-standing genetic variation in natural E. huxleyi populations will likely be important for these populations to adapt to a rapidly changing ocean (Lohbeck et al. 2012; Reusch and Boyd 2013).

\section{Acknowledgments}

Y. Zhang and R. Klapper contributed equally to this article and share the first authorship. We thank Andrea Ludwig for dissolved inorganic carbon measurements, Jana Meyer for total alkalinity measurements, and Scarlett Sett, Allanah Paul, and Silke Lischka for fruitful discussions about the data set. We gratefully acknowledge the reviewers for their useful comments. This work was supported by the German Federal Ministry of Education and Research (Bundesministerium für Bildung und Forschung) in the framework of the collaborative project Biological Impacts of Ocean Acidification (BIOACID). We also thank Sarah L. Eggers for providing E. huxleyi isolates from the Azores and the China Scholarship Council (CSC) for its support of Yong Zhang.

\section{References}

Agrawal, A. A., J. K. Conner, and S. Rasmann. 2010. Tradeoffs and negative correlations in evolutionary ecology, p. 243-268. In M. A. Bell, W. F. Eanes, D. J. Futuyma and J. S. Levinton [eds.], Evolution after Darwin: The first 150 years. Sinauer Associates.

Bach, L. T., U. Riebesell, And K. G. Schulz. 2011. Distinguishing between the effects of ocean acidification and ocean carbonation in the coccolithophore Emiliania huxleyi. Limnol. Oceanogr. 56: 2040-2050, doi:10.4319/lo.2011.56.6.2040

Boyd, P. W., AND OTHERs. 2013. Marine phytoplankton temperature versus growth responses from polar to tropical watersoutcome of a scientific community-wide study. PLoS One 8: e63091, doi:10.1371/journal.pone.0063091

BradShaw, A. D. 1965. Evolutionary significance of phenotypic plasticity in plants. Adv. Genet. 13: 115-155, doi:10.1016/ S0065-2660(08)60048-6
BRAND, L. E. 1982. Genetic variability and spatial patterns of genetic differentiation in the reproductive rates of the marine coccolithophores Emiliania huxleyi and Gephyrocapsa oceanica. Limnol. Oceanogr. 27: 236-245, doi:10.4319/lo.1982.27.2.0236

BRookfield, J. F. Y. 1996. A simple new method for estimating null allele frequency from heterozygote deficiency. Mol. Ecol. 5: 453-455, doi:10.1046/j.1365-294X.1996.00098.x

Buitenhuis, E. T., T. Pangerc, D. J. Franklin, C. L. Quéré, And G. MaLin. 2008. Growth rates of six coccolithophorid strains as a function of temperature. Limnol. Oceanogr. 53: 1181-1185, doi:10.4319/1o.2008.53.3.1181

Collins, S., B. Rost, and T. A. Rynearson. 2013. Evolutionary potential of marine phytoplankton under ocean acidification. Evol. Appl. 7: 140-155, doi:10.1111/eva.12120

Conte, M. H., A. Thompson, D. Lesley, and R. Harris. 1998. Genetic and physiological influences on the alkenone/alkenoate versus growth temperatures relationship in Emiliania huxleyi and Gephyrocapsa oceanica. Geochim. Cosmochim. Acta 62: 51-68, doi:10.1016/S0016-7037(97)00327-X

Cook, S. S., R. C. Jones, R. E. Vaillancourt, and G. M. HallegraefF. 2013. Genetic differentiation among Australian and Southern Ocean populations of the ubiquitous coccolithophore Emiliania huxleyi (Haptophyta). Phycologia 52: 368-374, doi:10.2216/12-111.1

Danbara, A., And Y. Shiraiwa. 1999. The requirement for selenium for the growth of marine coccolithophorids, Emiliana huxleyi, Gephyrocapsa oceanica and Helladosphaera sp. (Prymnewsiophyceae). Plant Cell Physiol. 40: 762-766, doi:10.1093/oxfordjournals.pcp.a029603

De Jong, G. 1990. Quantitative genetics of reaction norms. J. Evol. Biol. 3: 447-468, doi:10.1046/j.1420-9101.1990. 3050447.x

Dickson, A. G., J. D. Afghan, and G. C. Anderson. 2003. Reference materials for oceanic $\mathrm{CO}_{2}$ analysis: A method for the certification of total alkalinity. Mar. Chem. 80: 185-197, doi:10.1016/S0304-4203(02)00133-0

Evanno, G., S. Regnaut, and J. Goudet. 2005. Detecting the number of clusters of individuals using the software Structure: A simulation study. Mol. Ecol. 14: 2611-2620, doi:10.1111/ j.1365-294X.2005.02553.x

Excoffier, L., G. Laval, And S. Schneider. 2005. Arlequin (version 3.0): An integrated software package for population genetics data analysis. Evol. Bioinf. 1: 47-50. http://cmpg. unibe.ch/software/arlequin3

Fernández, E., E. Marañón, D. S. Harbour, S. Kristiansen, and B. R. Heimdal. 1996. Patterns of carbon and nitrogen uptake during blooms of Emiliania huxleyi in two Norwegian fjords. J. Plankton Res. 18: 2349-2366, doi:10.1093/plankt/ 18.12.2349

Flombaum, P., And others. 2013. Present and future global distributions of the marine Cyanobacteria Prochlorococcus and Synechococcus. Proc. Natl. Acad. Sci. USA 110: 9824-9829, doi:10.1073/pnas.1307701110

Gsell, A. S., L. N. De Senerpont-Domis, A. PrzytulskaBartosiewicz, W. M. MooiJ, E. Van Donk, and B. W. IBELINGS. 2012. Genotype-by-temperature interactions may help to maintain clonal diversity in Asterionella Formosa (Bacillariophyceae). J. Phycol. 48: 1197-1208, doi:10.1111/ j.1529-8817.2012.01205.x

Guillard, R. R., AND J. H. Ryther. 1962. Studies of marine planktonic diatoms. I. Cyclotella nana Hustedt, and Detonulaconfervacea (cleve) Gran. Can. J. Microbiol. 8: 229-239, doi:10.1139/m62-029

Huey, R. B., And J. G. Kingsolver. 1989. Evolution of thermal sensitivity of ectotherm performance. Trends Ecol. Evol. 4: 131-135, doi:10.1016/0169-5347(89)90211-5 
, AND R. D. Stevenson. 1979. Integrating thermal physiology and ecology of ectotherms: A discussion of approaches. Am. Zool. 19: 357-366, doi:10.1093/icb/19.1.357

Iglesias-Rodríguez, M. D., O. M. Schofield, J. Batley, L. K. Medlin, and P. K. Hayes. 2006. Intraspecific genetic diversity in the marine coccolithophore Emiliania huxleyi (Prymnesiophyceae): The use of microsatellite analysis in marine phytoplankton population studies. J. Phycol. 42: 526-536, doi:10.1111/j.1529-8817.2006.00231.x

Intergovernmental Panel on Climate Change. 2013. Climate change 2013: The physical science basis. Contribution of Working Group I to the Fifth Assessment Report of the Intergovernmental Panel on Climate Change. Cambridge Univ. Press.

Izem, R., And J. G. Kingsolver. 2005. Variation in continuous reaction norms: Quantifying directions of biological interest. Am. Nat. 166: 277-289, doi:10.1086/431314

Kester, D., I. W. Duedall, D. N. Connors, and R. M. Pytкowicz. 1967. Preparation of artificial seawater. Limnol. Oceanogr. 1: 176-179, doi:10.4319/lo.1967.12.1.0176

Kremp, A., A. Godhe, J. Egardt, S. Dupont, S. Suikkanen, S. Casabianca, and A. Penna. 2012. Intraspecific variability in the response of bloom-forming marine microalgae to changed climate conditions. Ecol. Evol. 2: 1195-1207, doi:10.1002/ ece 3.245

LeducQ, J. B., AND others. 2014. Local climatic adaptation in a widespread microorganism. Proc. R. Soc. B 281: 1471-2954, doi:10.1098/rspb.2013.2472

Lewis, E., And D. W. R. Wallace. 1998. Program developed for $\mathrm{CO}_{2}$ system calculations [Internet]. ORNL/CDIAC-105. Carbon Dioxide Information Analysis Centre, Oak Ridge National Laboratory, U.S. Department of Energy. Available from http://cdiac.ornl.gov/oceans/co2rprt.html. (accessed 12 June 2007).

Locarnini, R. A., A. V. Mishonov, J. I. Antonov, T. P. Boyer, AND H. E. GARCIA. 2006. World ocean atlas 2005. V. 1: Temperature. p. 123-134. In S. Levitus [ed.], NOAA Atlas NESDIS 61. U.S. Government Printing Office.

Lohbeck, K. T., U. Riebesell, and T. B. H. Reusch. 2012. Adaptive evolution of a key phytoplankton species to ocean acidification. Nat. Geosci. 5: 346-351, doi:10.1038/ngeo1441

McInTyre, A, AND A. W. H. BÉ. 1967. Modern coccolithophoridae of the Atlantic Ocean-I. Placoliths and Cyrtoliths. Deep-Sea Res. 14: 561-597, doi:10.1016/0011-7471(67)90065-4

Medlin, L. K., M. Lange, and E. M. Nöthig. 2000. Genetic diversity in the marine phytoplankton: A review and a consideration of Antarctic phytoplankton. Antarct. Sci. 12: 325-333, doi:10.1017/ S0954102000000389

Palumbi, S. R. 1994. Genetic divergence, reproductive isolation, and marine speciation. Ann. Rev. Ecol. Syst. 25: 547-572, doi:10.1146/annurev.es.25.110194.002555

Pritchard, J. K., M. Stephens, and P. Donnelly. 2000. Inference of population structure using multilocus genotype data. Genetics 155: 945-959.

Read, B. A., AND Others. 2013. Pan genome of the phytoplankton Emiliania underpins its global distribution. Nature 499: 209-213, doi:10.1038/nature12221
Reusch, T. B. H. 2014. Climate change in the oceans: Evolutionary versus phenotypically plastic responses of marine animals and plants. Evol. Appl. 7: 104-122, doi:10.1111/eva.12109

- AND P. W. Boyd. 2013. Experimental evolution meets marine phytoplankton. Evolution 67: 1849-1859, doi:10.1111/ evo. 12035

Riebesell, U., and P. D. Tortell. 2011. Effects of ocean acidification on pelagic organisms and ecosystems. p. 99-121. In J. P. Gattuso and L. Hansson [eds.], Ocean acidification. Oxford Univ. Press.

Rynearson, T. A., And E. V. Armbrust. 2004. Genetic differentiation among populations of the planktonic marine diatom Ditylum brightwelli (Bacillariophyceae). J. Phycol. 40: 34-43, doi:10.1046/j.1529-8817.2004.03089.x

Samuelsen, T. J. 1970. The biology of six species of Anomura (Crustacea, Decapoda) from Raunefjorden, western Norway. Sarsia 45: 25-52.

Schaum, E., B. Rost, A. J. Millar, and S. Collins. 2012. Variation in plastic responses of a globally distributed picoplankton species to ocean acidification. Nat. Clim. Change 3: 298-302, doi:10.1038/nclimate1774

Sgrò, C. M., And A. A. Hoffmann. 2004. Genetic correlations, tradeoffs and environmental variation. Heredity 93: 241-248, doi:10.1038/sj.hdy.6800532

Tatters, A. O., AND Others. 2013. Short- and long-term conditioning of a temperate marine diatom community to acidification and warming. Phil. Trans. R. Soc. B 368: 20120437, doi:10.1098/rstb.2012.0437

Thomas, M. K., C. T. Kremer, C. A. Klausmeier, and E. Litchman. 2012. A global pattern of thermal adaptation in marine phytoplankton. Science 338: 6110, 1085-1088, doi:10.1126/science. 1224836

Van Oosterhout, C., W. F. Hutchinson, D. P. M. Wills, and P. ShIPLEY. 2004. MICRO-CHECKER: Software for identifying and correcting genotyping errors in microsatellite data. Mol. Ecol. Notes 4: 535-538, doi:10.1111/j.1471-8286.2004. 00684.X

Winter, A., J. Henderiks, L. Beaufort, R. E. M. Rickaby, and C. W. Brown. 2013. Poleward expansion of the coccolithophore Emiliania huxleyi. J. Plankton Res. 0: 1-10, doi:10.1093/plankt/fbt110

Wisshak, M., A. Form, J. Jakobsen, And A. Freiwald. 2010. Temperate carbonate cycling and water mass properties from intertidal to bathyal depths (Azores). Biogeosciences 7: 2379-2396, doi:10.5194/bg-7-2379-2010

WrigHT, S. 1978. Evolution and the genetics of populations. V. 4: Variability within and among natural populations. Univ. of Chicago Press.

Associate editor: John Albert Raven

Received: 19 December 2013 Accepted: 11 May 2014 Amended: 24 May 2014 